44 (1) | 2015

Varia

París, 29-31 de enero de 2015

\title{
Coloquio Internacional «Saberes, ciencias, técnicas y construcción del Estado en Iberoamérica, 1790-1870»
}

\section{Clément Thibaud}

\section{OpenEdition}

Journals

Edición electrónica

URL: http://journals.openedition.org/bifea/7452

DOI: 10.4000/bifea.7452

ISSN: 2076-5827

Editor

Institut Français d'Études Andines

Edición impresa

Fecha de publicación: 1 abril 2015

Paginación: 161-163

ISSN: 0303-7495

Referencia electrónica

Clément Thibaud, «Coloquio Internacional «Saberes, ciencias, técnicas y construcción del Estado en |beroamérica, 1790-1870» », Bulletin de l'Institut français d'études andines [En línea], 44 (1) | 2015,

Publicado el 08 mayo 2015, consultado el 06 noviembre 2020. URL : http://journals.openedition.org/ bifea/7452 ; DOI : https://doi.org/10.4000/bifea.7452

\section{(c)}

Les contenus du Bulletin de l'Institut français d'études andines sont mis à disposition selon les termes de la licence Creative Commons Attribution - Pas d'Utilisation Commerciale - Pas de Modification 4.0 International. 


\section{COLOQUIO INTERNACIONAL «SABERES, CIENCIAS, TÉCNICAS Y CONSTRUCCIÓN DEL ESTADO EN IBEROAMÉRICA, 1790-1870»}

París, 29-31 de enero de 2015

En las dos últimas décadas, la historia de la ciencia se ha renovado al incluir espacios no europeos, especialmente las Américas ibéricas, y al estudiar las relaciones entre saber y poder. En la actualidad poseemos investigaciones cada vez más numerosas sobre las ciencias imperiales, sobre la contribución de las colonias a los avances del conocimiento —en particular de la historia natural-, sobre las Luces y sobre las relaciones entre ciencias, revoluciones e independencias. También hay un auge de los estudios sobre el papel de las ciencias y de los saberes en los procesos de consolidación de los Estados-naciones a partir del último tercio del siglo XIX, auge que coincide con la afirmación del paradigma positivista y con la integración de América Latina en los flujos de la economía mundial. Sin embargo, el interés de los latinoamericanistas por el período intermedio que va de la llustración al cientismo apenas empieza a manifestarse. Este vacío lo explicaría una visión que sigue siendo bastante común, y según la cual las Américas ibéricas habrían vivido «décadas perdidas» en el campo de la construcción estatal, en el terreno de los resultados económicos y en la integración social y cultural de poblaciones esencialmente diversas. 
Colloque international

Savoirs, sciences, techniques et construction étatique en Amérique ibérique, 1790-1870

du jeudi 29 au samedi 31 janvier 2015
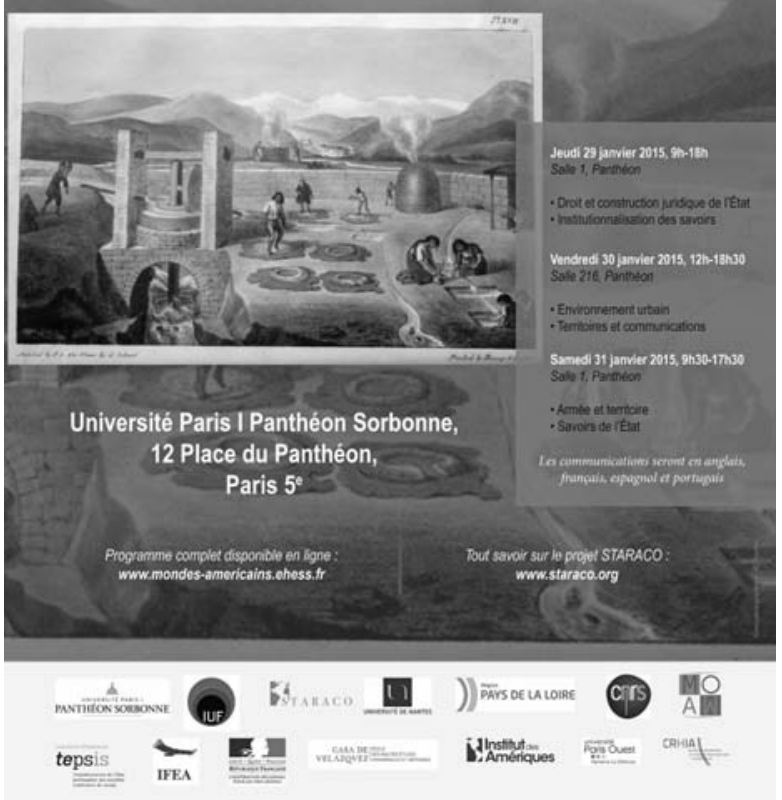

Con este coloquio, organizado por Annick Lempérière (Université Paris I Panthéon-Sorbonne) y Clément Thibaud (Université de Nantes) se propuso explorar la hipótesis inversa y poner de relieve las modalidades a través de las cuales sobrevivió, se transmitió y se transformó el legado de las Luces imperiales y coloniales, así como los procesos mediante los cuales las sociedades iberoamericanas -incluyendo a Brasil y las colonias españolas del Caribe - se prepararon a finales del siglo XIX para sacar todas las consecuencias del nuevo paradigma científico con una sorprendente celeridad.

El propósito de los organizadores fue replantear la cuestión del tránsito de «los imperios a las naciones» considerándolo desde el punto de vista de las relaciones entre saberes, ciencias, técnicas y construcción estatal. Si es cierto que a escala global la verdadera «revolución científica» tuvo lugar entre las últimas décadas del siglo XVIII y la mitad del siglo XIX, coincidiendo por lo tanto con la edad de las revoluciones y con la revolución industrial, se preguntó de qué manera las sociedades iberoamericanas participaron de esa revolución científica, cómo dicha revolución se articuló a la construcción de su organización política como Estados nacionales, y cómo surgieron tanto nuevas formas de gobierno de los territorios y de las poblaciones, como nuevas modalidades de acción estatal y política pública.

Considerando que en cualquier sociedad el conocimiento es un producto social, se intentó ante todo identificar a los actores concretos, individuales y colectivos, de una historia política, social, cultural y material de los saberes en las Américas ibéricas. ¿Cuáles fueron las contribuciones concretas de los administradores, estadistas, militares, científicos, juristas, publicistas y también de los hombres de negocios y de los empresarios a la producción, circulación y difusión de los conocimientos científicos y técnicos? ¿En qué redes y en qué escenarios de sociabilidad discutieron y compartieron sus saberes? ¿Bajo qué criterios los consideraron útiles para el gobierno y para el desarrollo económico? ¿Cuáles fueron los círculos sociales en los cuales se concretó la circulación entre conocimientos científicos o técnicos y la acción pública? ¿Mediante qué tipo de circulaciones (exilios, viajes de estudios, intercambios de correspondencia científica o administrativa, publicaciones, 
etc.) se relacionaron en los espacios nacionales y en el espacio euroamericano? ¿Qué tipo de conexiones e intercambios establecieron con los círculos científicos europeos y estadounidenses? ¿Qué papel tuvo la esfera pública, la opinión y la circulación de los impresos en la socialización de los saberes —trátese de la higiene pública, la máquina de vapor o el sistema métrico- - y qué efectos tuvo esa socialización en el papel y las funciones del Estado? Finalmente, ¿̇cuál fue el impacto del advenimiento de los nuevos saberes y técnicas sobre las formas de autoridad social, política y religiosa?

Sabiendo cuán dudosa fue la centralidad e institucionalización del «Estado» durante este período, se consideró al «Estado» desde un enfoque concreto y plural: el gobierno nacional, sus ministerios, burócratas y administradores, los gobiernos de los estados de régimen federal, los prefectos y jefes políticos de las provincias, y de los departamentos, y los ayuntamientos. ¿Qué ocurrió con los «saberes de Estado» durante el período? ¿Cómo lograron las autoridades conseguir informaciones sobre la población, el territorio, la producción y la actividad comercial? ¿De qué manera reutilizaron y actualizaron los saberes de Estado acumulados en la época imperial? ¿Cómo nació la estadística pública? ¿Con qué agentes pudo contar el Estado para juntar esos saberes, y con qué saberes, teóricos y prácticos contaron los agentes para llevar a cabo sus tareas? ¿Tomaron iniciativas para mejorar o reformar el funcionamiento de las oficinas? ¿Siguieron siendo efectivas las grandes «ordenanzas» de la administración imperial, o fueron poco a poco ignoradas o reformadas? ¿Cómo se planteó el problema de la eficacia administrativa y cómo se vinculó ese problema con la implicación del Estado en la actividad económica? En cuanto a los saberes se tomó en cuenta un espectro muy amplio, desde las disciplinas científicas hasta los saberes prácticos empleados en la actividad minera o en los primeros ferrocarriles, en los primeros bancos o en las plantaciones, pasando por los saberes de gobierno tales como el Derecho bajo sus múltiples modalidades (civil, comercial, público y constitucional), o bien la economía política, el derecho administrativo y la ciencia administrativa. ¿Qué lugar ocupó la institucionalización de estos saberes y cuáles fueron sus agentes (privados o estatales)? ¿Cómo y mediante qué actores circularon en las Américas ibéricas y en el espacio euroamericano? ¿Cómo, de manera concreta, circularon entre la esfera intelectual y la de la práctica gubernamental o económica? 